\title{
A systemic parvo-like virus in the freshwater crayfish Cherax destructor
}

\author{
Brett Edgerton ${ }^{1, *}$, Richard Webb $^{2}$, Max Wingfield ${ }^{3}$ \\ 'Department of Biomedical and Tropical Veterinary Sciences, James Cook University of North Queensland, Townsville, \\ Queensland 4811, Australia
}

${ }^{2}$ Department of Microbiology and Centre for Microscopy and Microanalysis, University of Queensland, Queensland 4072, Australia

${ }^{3}$ Fisheries Department, Department of Primary Industries South Australia, 25 Grenfell St., Adelaide, South Australia 5000, Australia

\begin{abstract}
Systemic Cowdry Type A inclusions (CAs) were observed in a moribund Cherax destructor collected at an aquaculture farm in South Australia. Inclusions were most common in the gills and were associated with multifocal necrosis of the main gill axis and lamellae. The hepatopancreas was necrotic; however, only one CA was observed in the interstitial tissues. CAs were associated with necrosis in the abdominal and gut musculature. CAs were also observed in the spongy connective tissues and the epicardium. Empty capsids $(17.5 \pm 0.5 \mathrm{~nm})$ and microfilaments were most commonly observed within these inclusions by transmission electron microscopy. Complete icosahedral viral particles $(20.8 \pm 1.2 \mathrm{~nm})$ were difficult to distinguish within the viroplasm, but were visualised better in aggregates between the viroplasm and the inner nuclear membrane. The nucleolus was closely associated with the developing viroplasm, and was hypertrophied and segregated into its fibrillar and granular components. The virus was named Cherax destructor systemic parvo-like virus (CdSPV) on the basis of its histopathology, cytopathology and morphology. CdSPV is the first systemic virus described in a freshwater crayfish.
\end{abstract}

KEY WORDS: Crayfish - Cherax destructor Systemic parvo-like virus - Histopathology Cytopathology

\section{INTRODUCTION}

Viruses have been described in a number of freshwater crayfish species since the discovery of the initial freshwater crayfish virus, Cherax quadricarinatus bacilliform virus, by Anderson \& Prior (1992). Most are intranuclear bacilliform viruses which infect the gut (Hedrick et al. 1995, Edgerton 1996, Edgerton et al. 1996). The one exception is Cherax Giardiavirus-like virus (CGV), a dsRNA virus which infects hepatopancreatocytes in C. quadricarinatus (Edgerton et al. 1994).

Parvoviruses assigned to the Densovirinae subfamily infect arthropods (Murphy et al. 1995), including a number of commercially important crustaceans. Hepa-

\footnotetext{
- Present address: Queensland Department of Primary Industries, Oonoonba Veterinary Laboratory, PO Box 1085, Townsville, Queensland 4810, Australia.

E-mail: edgertb@dpi.qld.gov.au
}

topancreatic parvovirus (HPV) infects the hepatopancreatocytes of a range of penaeid species (Lightner \& Redman 1985, Lightner 1996), and a morphologically indistinguishable virus also infects the giant freshwater prawn Macrobrachium rosenbergii (Anderson et al. 1990). Mari \& Bonami (1988) described a systemic parvovirus, which they named PC84, in the crab Carcinus mediterraneus. Infectious hypodermal and haematopoietic necrosis virus (IHHNV) is possibly the best known crustacean parvovirus, due to its well documented pathogenicity and its wide host and geographical range (Brock \& Lightner 1990). IHHNV has also been described in experimental hybrid penaeids in Australia (Owens et al. 1992). Lymphoidal parvolike virus was described in 3 penaeid species in Australia (Owens et al. 1991). The viruses PC84, HPV and IHHNV have been characterised physicochemically to confirm their relatedness to the Parvoviridae (Mari \& Bonami 1988, Bonami et al. 1990, Bonami et al. 1995). The Australian viruses do not react with DNA probes 
for these viruses (Lightner 1996) and are uncharacterised

A parvo-like virus was associated with Cowdry Type A inclusions in a moribund Cherax destructor during an ongoing surveillance of farmed crayfish for disease. This paper describes the histopathology, cytopathology and morphology of the agent.

\section{MATERIALS AND METHODS}

One moribund Cherax destructor was collected at an aquaculture farm in South Australia. The crayfish was sacrificed immediately by severing the cephalothorax from the abdomen. The cephalothorax was then split longitudinally and placed in Davidson's solution with the abdomen. Tissues were processed and histological sections were prepared conventionally (Culling et al. 1985) on arrival at the laboratory. Sections were stained with H\&E, Feulgen and phloxine and tartrazine stains. Histological sections were viewed using a Leitz Orthoplan microscope

Davidson's fixed gill tissues were also used for electron microscopy. Gill tissue was re-fixed in $3 \%$ glutaraldehyde in $0.1 \mathrm{M}$ cacodylate buffer overnight at $4^{\circ} \mathrm{C}$, washed 3 times in $0.1 \mathrm{M}$ cacodylate buffer, post-fixed for $1 \mathrm{~h}$ at room temperature in $1 \%$ osmium tetroxide in $0.1 \mathrm{M}$ cacodylate buffer, washed 3 times in $0.1 \mathrm{M}$ cacodylate buffer, dehydrated through an acetone series, and embedded in Epon. Ultrathin sections were cut using a Reichert-Jung Ultracut E ultramicrotome, stained with uranyl acetate and lead citrate, and were viewed using a Jeol 1010 transmission electron microscope.

\section{RESULTS}

\section{Gross symptoms}

The crayfish was extremely morbid and was easily collected by hand on the pond bank. The ventral surface of the abdomen exhibited patches of opaque musculature

\section{Light microscopy}

Intranuclear, Cowdry Type A inclusions (CAs) were observed systemically in the crayfish and were most common in the gills. Affected nuclei were hypertrophied, had a thin rim of marginated chromatin, and contained a single eosinophilic CA in the centre. The CAs were neutral to very lightly phloxophilic and were Feulgen-negative. The nucleolus, when discernable, was basophilic and was closely associated with the inclusion. Smaller, presumably earlier, inclusions always developed centrally and were lightly eosinophilic.

The gills contained extensive necrotic foci characterised by masses of pyknotic and karyorrhectic nuclei, and major haemocytic infiltration, melanisation and nodulation. Pyknotic nuclei and haemocytic nodules were diffuse throughout non-necrotic tissue. CAs were often observed in gill epithelial cells, and in unidentifiable cells, close to necrotic areas and in areas becoming necrotic (Fig. 1). Gill epithelial cells with hypertrophic nuclei, rarefied chromatin and enlarged nucleoli, but without CAs, were common throughout the gills.

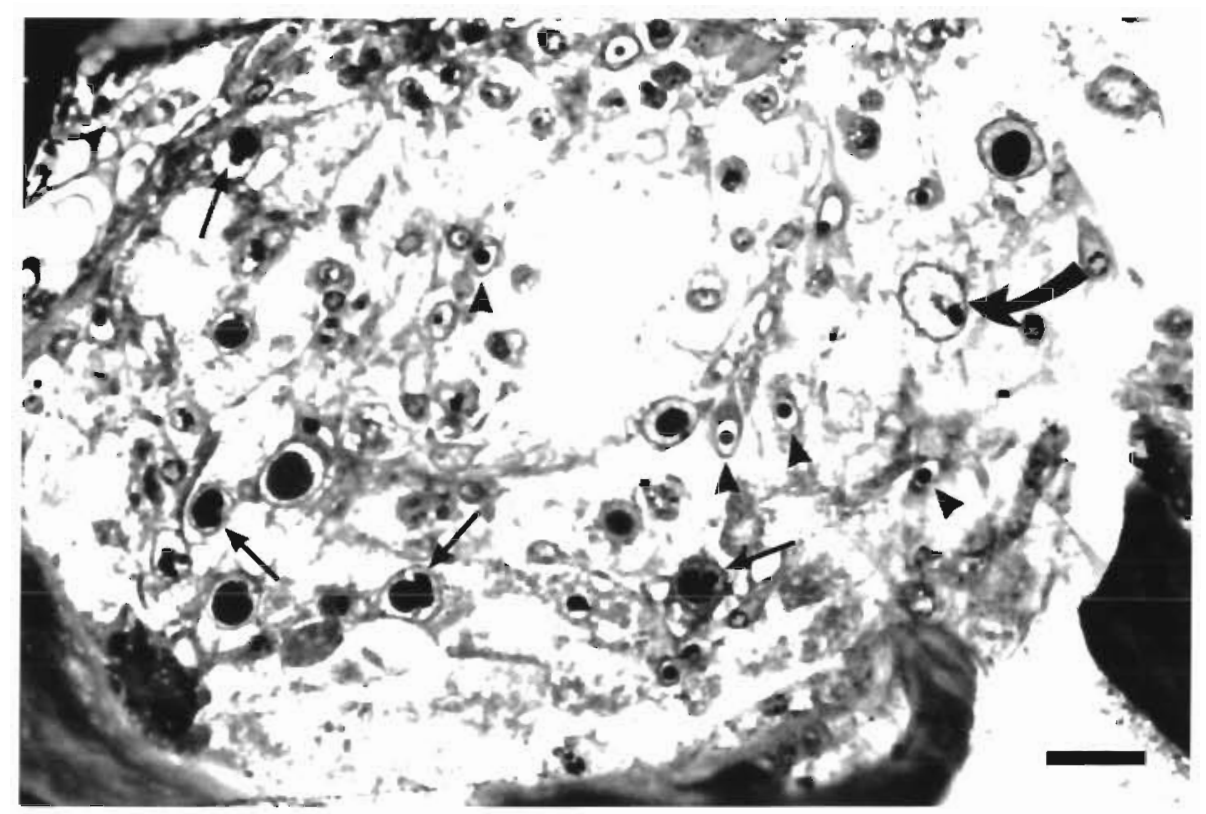

Fig. 1. Light microscopy of Cherax destructor systemic parvo-like virus in Cherax destructor. Many Cowdry Type A intranuclear inclusions in the gill. Note that the inclusions are rounded and are closely associated with the nucleolus (arrows). Note also the many pyknotic nuclei in the area (arrowheads). This area is near to a completely necrotic and melanised area. A hypertrophic nucleus with rarefied chromatin and hypertrophic nucleolus is also present (curved arrow). Toluidine blue. Scale bar $=27 \mu \mathrm{m}$ 
The hepatopancreas and midgut were extensively necrotic. Hepatopancreatocytes were almost exclusively B-cells. Haemocytic infiltrates and small melanitic foci were common in the interstitial tissues of the hepatopancreas and in the midgut submucosa. Haemolymph vessels were only present peripherally in the hepatopancreas, and the endothelial cells and infiltrating haemocytes were usually voluminous or pyknotic. The nucleus of an unidentified cell associated with a haemolymph vessel in the hepatopancreas contained a CA, as did a hindgut myoepithelial cell. Cellular debris and bacteria were distributed throughout the entire gut.

CAs, pyknotic and karyorrhectic nuclei, and haemocytic infiltrates and nodules were also observed in the epicardium, abdominal muscle and spongy connective tissues. Hypertrophic nuclei with rarefied chromatin and prominent nucleoli, but without inclusions, were also common in these tissues.

\section{Electron microscopy}

Gill cells containing CAs were hypertrophied, and had marginated and rarefied chromatin (Fig. 2). A rounded, granular viroplasm was located centrally, closely associated with the hypertrophied nucleolus. The viroplasm contained mostly filamentous structures and rounded $17.5 \pm 0.5 \mathrm{~nm}(\mathrm{n}=7$ ) particles with electron-lucent centres, presumed to be empty capsids (Fig. 3). Electron-dense, $20.8 \pm 1.2 \mathrm{~nm}(\mathrm{n}=6)$ particles were difficult to distinguish within the inclusion, but were visualised better in aggregates between the viroplasm and the inner nuclear membrane. Some particles were clearly hexagonal or pentagonal, indicating an icosahedral symmetry. In some nuclei, the area between the inclusion and the nuclear membrane was full of empty capsids. Nucleolar components of infected cells had segregated with the filamentous component vacuolated and surrounded by the granular component. The granules of the granular component were more sharply defined and packed densely together, and fully formed virions were adjacent to the body.

In some nuclei, the nucleolus was hypertrophic, had segregated, and the viroplasm was only just forming (Fig. 4). The developing viroplasm was round and consisted of groups of long microfilaments associated with mostly empty capsids.

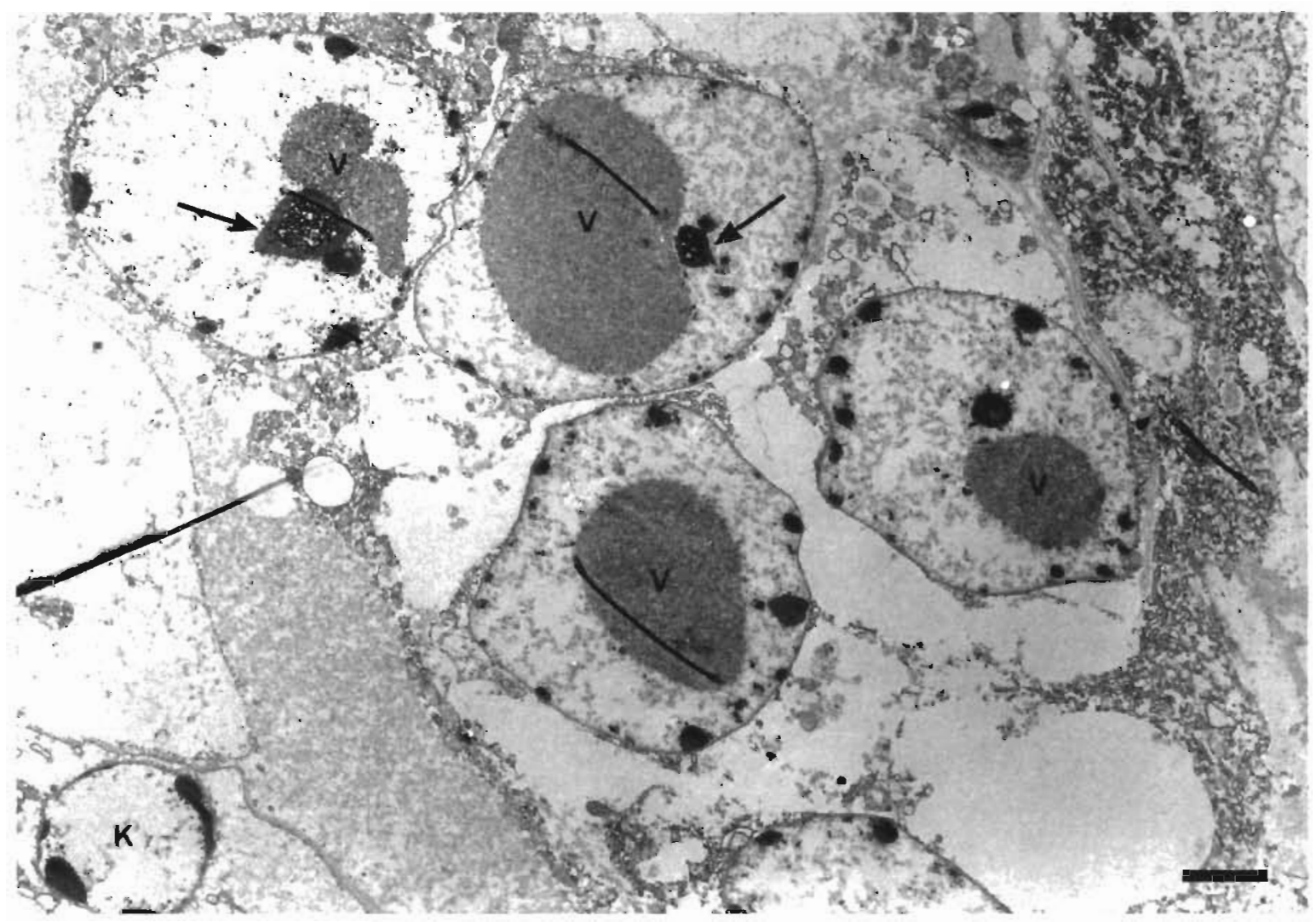

Fig. 2. Electron microscopy of CdSPV in Cherax destructor gill. Low magnification of 4 infected nuclei. Note that chromatin is marginated and rarefied, and the rounded viroplasm (V) is closely associated with the segregated nucleolus (arrows). A karyorrhectic nucleus is adjacent $(\mathrm{K})$. Uranyl acetate and lead citrate. Scale bar $=2.4 \mu \mathrm{m}$ 


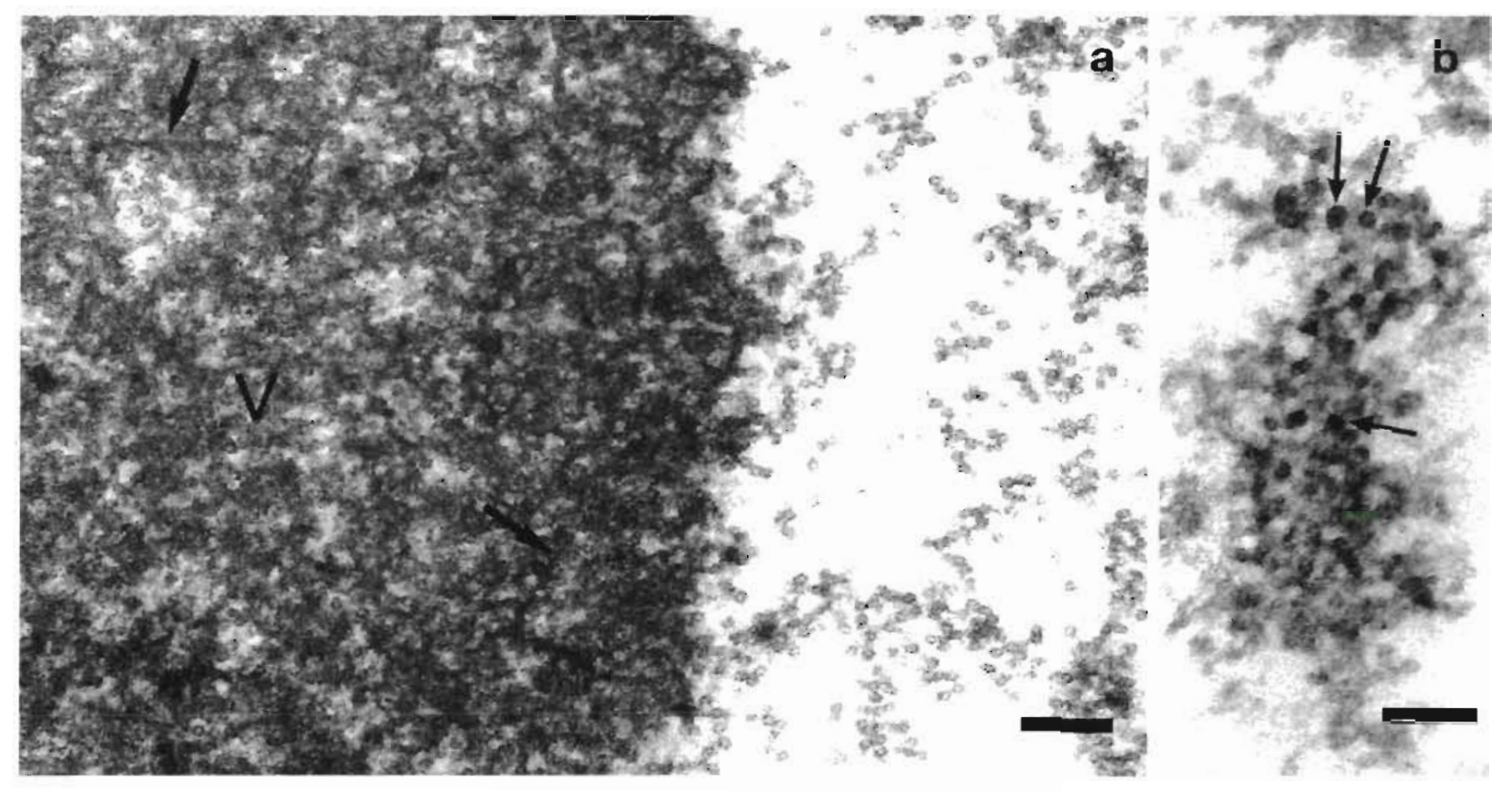

Fig. 3. Electron microscopy of CdSPV in Cherax destructor gill. (a) Higher magnification of CdSPV viroplasm (V) and surrounding area. Note that empty capsids and microfilaments (arrows) are most common within the viroplasm. Empty capsids are abundant in the area surrounding the viroplasm. Uranyl acetate and lead citrate. Scale bar $=130 \mathrm{~nm}$. (b) Cluster of complete CdSPV virions. Note that many virions are angular (arrows). Uranyl acetate and lead citrate. Scale bar $=100 \mathrm{~nm}$

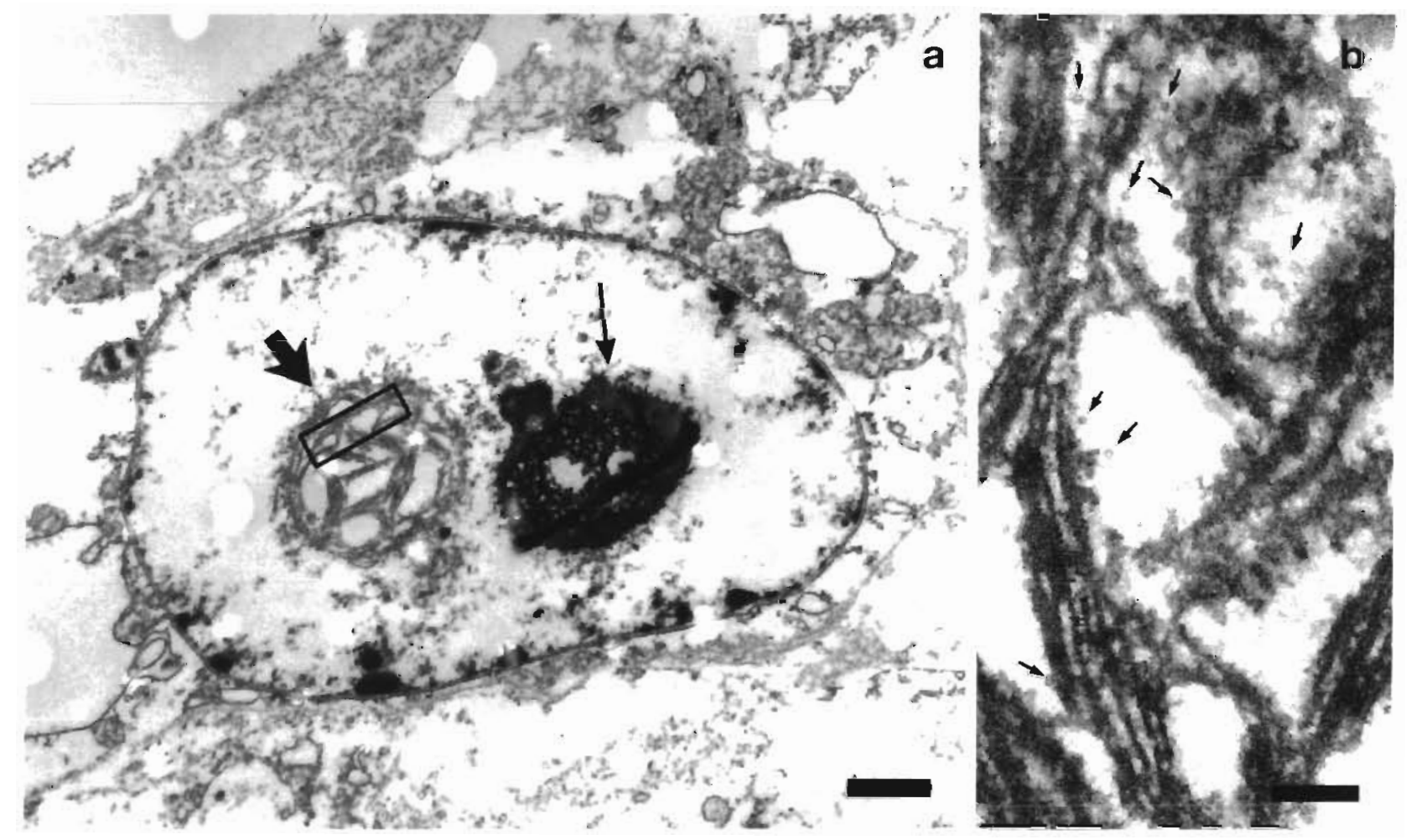

Fig. 4. Electron microscopy of CdSPV in Cherax destructor gill. (a) A nucleus in a presumptive early stage of infection. Note that the nucleolus is hypertrophied and segregated (thin arrow); the fibrous component is vacuolated and is completely surrounded by the granular component. The developing viroplasm (thick arrow) is close to the nucleolus and is round. Uranyl acetate and lead citrate. Scale bar $=1.2 \mu \mathrm{m}$. (b) Higher magnification of the forming viroplasm within the area indicated on (a). Note that empty capsids (arrows) are associated with long microfilaments. Uranyl acetate and lead citrate. Scale bar $=150 \mathrm{~nm}$ 


\section{DISCUSSION}

This is the first systemic virus found in a freshwater crayfish. This agent is clearly different from bacilliform viruses which infect the gut of freshwater crayfish (Anderson \& Prior 1992, Hedrick et al. 1995, Edgerton 1996, Edgerton et al. 1996). It also differs significantly in its tropism, histopathology and cytopathology from CGV which infects hepatopancreatocytes of Cherax quadricarinatus (Edgerton et al. 1994). This virus is similar in size and produces cytopathology reminiscent of parvoviruses; it is between 18 and $25 \mathrm{~nm}$ in diameter, and it replicates in the nucleus in close association with the nucleolus, which is segregated into its fibrillar and granular components. The agent is therefore named Cherax destructor systemic parvo-like virus (CdSPV).

CdSPV was associated with major necroses of vital organs. The CAs were found in close proximity to the large necrotic areas in the gills, and in smaller foci beginning to necrotise. A CA was observed interstitially in the massively necrotic hepatopancreas. CAs were associated with necrotic muscle. Whilst these changes no doubt resulted in the extreme morbidity of this animal, it is impossible to fully understand the involvement of CdSPV with these changes. The pathogenicity of CdSPV is therefore unknown.

The ultrastructural pathology of CdSPV is reminiscent of HPV. Similarly to CdSPV, HPV produces a single rounded virogenic stroma which is closely associated with the nucleolus (Lightner \& Redman 1985). Microfibrils or microtubules are also apparent throughout the viroplasm. Intranuclear bodies, which are characteristically embedded in the viroplasm of HPV (Lightner \& Redman 1985) and other parvoviruses (Garzon \& Kurstak 1976), were not observed in CdSPV. However, the absence of such structures in these preparations may be due to sub-optimal fixation. As the names suggest, HPV has a different tropism to CdSPV. In this respect, CdSPV is similar to PC84 and IHHNV. PC84 also produces microtubules; however, virions were not associated with these, and the authors considered that these structures may characterise abortive morphogenesis (Mari \& Bonami 1988). Neither PC84 nor IHHNV produce a rounded virogenic stroma, and nucleoli dissolve following infection by both viruses (Lightner et al. 1983, Mari \& Bonami 1988). Nucleolar hypertrophy and segregation is characteristic of densovirus (Garzon \& Kurstak 1976) as well as other virus infections; however, this is the first description of such a phenomenon in crustacean parvoviruses. The vacuolation of the fibrous component is reminiscent of canine parvovirus (Paradiso et al. 1982).

CdSPV is the second virus found in Cherax destructor. Virtually nothing is known of the prevalence or impact of these viruses on the $C$. destructor aquaculture industry. $C$. destructor is the most economically important freshwater crayfish species in Australia, accounting for over $80 \%$ of annual production (various industry sources). Research into the basic biology of these viruses is required to assess the potential threat of these viruses to this developing industry

Acknowledgements. Laurie Reilly, Department of Biomedical and Tropical Veterinary Sciences, James Cook University, is thanked for histological preparations. The continued support of both Dr Leigh Owens, Department of Biomedical and Tropical Veterinary Sciences, James Cook University, and Prof. John McKenzie, Department of Microbiology, University of Queensland, is appreciated. This research was funded by an Australian Research Council Large Grant (A19332302)

\section{LITERATURE CITED}

Anderson IG, Law AT, Shariff M, Nash G (1990) A parvo-like virus in the giant freshwater prawn, Macrobrachium rosenbergii. J Invertebr Pathol 55:447-449

Anderson IG, Prior HC (1992) Baculovirus infections in the mud crab. Scylla serrata, and a freshwater crayfish, Cherax quadricarinatus, from Australia. J Invertebr Pathol 60:265-273

Bonami JR, Mari J, Poulos BT, Lightner DV (1995) Characterization of hepatopancreatic parvo-like virus, a second unusual parvovirus pathogenic for penaeid shrimps. J Gen Virol 76:813-817

Bonami JR, Trumper B, Mari J, Brehelin M, Lightner DV (1990) Purification and characterization of the infectious hypodermal and haematopoietic necrosis virus of penaeid shrimps. J Gen Virol 71:2657-2664

Brock JA, Lightner DV (1990) Diseases of Crustacea, 3.1: Diseases caused by microorganisms. In: Kinne $O$ (ed) Diseases of marine animals. Biologische Anstalt Helgoland, Hamburg, p 245-349

Culling CFA, Allison RT, Barr WT (1985) Cellular pathology techniques, 4 th edn. Butterworths, London

Edgerton B (1996) A new bacilliform virus in Australian Cherax destructor (Decapoda: Parastacidae) with notes on Cherax quadricarinatus bacilliform virus $=$ Cherax baculovirus). Dis Aquat Org 27:43-52

Edgerton B, Owens L, Glasson B, De Beer S (1994) Description of a small dsRNA virus from freshwater crayfish, Cherax quadricarinatus. Dis Aquat Org 18:63-69

Edgerton B, Paasonen P, Henttonen P, Owens L (1996) Description of a non-occluded baculovirus from the freshwater crayfish, Astacus astacus. J Invertebr Pathol 68: $187-190$

Garzon S, Kurstak E (1976) Ultrastructural studies on the morphogenesis of the densonucleosis virus (parvovirus). Virology 50:517-431

Hedrick RP, McDowell TS, Friedman CS (1995) Baculoviruses found in two species of crayfish from California. Aquaculture '95, Abstracts: 135

Lightner DV (1996) A handbook of pathology and diagnostic procedures for disease of Penaeid shrimp. World Aquaculture Society, Baton Rouge, Louisiana

Lightner DV, Redman RM (1985) A parvo-like virus disease of Penaeid shrimp. J Invertebr Pathol 45:47-53 
Lightner DV, Redman RM, Bell TA (1983) Infectious hypodermal and hematopoietic necrosis, a newly recognized virus disease of penaeid shrimp. J Invertebr Pathol 42:62-70

Mari J, Bonami JR (1988) PC 84, a parvo-like virus from the crab Carcinus mediterraneus: pathological aspects, ultrastructure of the agent, and first biochemical characterization. J Invertebr Pathol 51:145-156

Murphy FA, Fauquet CM, Mayo MA, Jarvis AW, Ghabrial SA, Summers MD, Martelli GP, Bishop DHL (1995) The classification and nomenclature of viruses: sixth report of the International Committee on Taxonomy of Viruses.

Responsible Subject Editor: J. E. Stewart, Dartmouth, Nova Scotia, Canada
Archives of Virology, Springer Verlag, Wien

Owens L, Anderson IG, Kenway M, Trott L, Benzie JAH (1992) Infectious hypodermal and haematopoietic necrosis virus (IHHNV) in a hybrid penaeid prawn from tropical Australia. Dis Aquat Org 14:219-228

Owens L, De Beer S, Smith J (1991) Lymphoidal parvoviruslike particles in Australian penaeid prawns. Dis Aquat Org 11:129-134

Paradiso PR, Rhode SL (III), Singer II (1982) Canine parvovirus: a biochemical and ultrastructural characterization. J Gen Virol 62:113-125

Manuscript first received: September 5, 1996

Revised version accepted: January 8, 1997 